\title{
O FUTEBOL COMO NEGÓCIO: UMA COMPARAÇÃO FINANCEIRA COM OUTROS SEGMENTOS
}

\author{
Grad. THADEU MIRANDA GASPARETTO \\ Faculdade de Educação Física e Desportos, Universidade Federal \\ de Juiz de Fora (Juiz de Fora - Minas Gerais - Brasil) \\ E-mail: gasparetto.thadeu@gmail.com
}

\begin{abstract}
RESUMO
O futebol é considerado um grande negócio desde o início do século passado. Apesar de diversos autores tentarem definir esta afirmação, o presente estudo demonstrou interesse em investigá-la através de outra perspectiva, objetivando comparar os grandes clubes esportivos com as principais empresas dos demais ramos empresariais, utilizando dados financeiros. Inicialmente, adotou-se como método a revisão bibliográfica em fontes secundárias, apresentando, posteriormente, etapas empírico-analíticas, ao realizar técnicas de coleta, tratamento e análise dos dados, com comparações entre os valores encontrados. Apesar deste esporte apresentar-se como um grande negócio devido aos valores de faturamento anual, ao utilizar como referência Brand Value (valor de marca), Market Value (valor de mercado) e receitas operacionais, essa investigação exibe como resultado a grande diferença econômica entre os clubes de futebol e as maiores empresas do Brasil e do mundo expondo, desta forma, a pequena parcela econômica que este esporte representa em relação às principais organizações mundiais.
\end{abstract}

PALAVRAS-CHAVE: Futebol; receitas operacionais; valor de marca; valor de mercado. 
Em 1905, Willian McGregor, então presidente da Football League, afirmou que "Football is a big business". O futebol, com o passar dos anos, foi ganhando notoriedade em todo mundo até se tornar a potência atual, sendo o esporte preferido no Brasil (KASZNAR; GRAÇA FILHO, 20 I 2), como também o mais popular em nosso planeta (STOLEN et al., 2005). Para mensurar a dimensão que esse esporte alcançou, a FIFA (Fédération Internacionale de Football Association) possui hoje 208 países e territórios associados, número superior ao do Comitê Olímpico Internacional e da Organização das Nações Unidas, que possuem 192 membros cada. Além disso, a ideia difundida no início do século $X X$ permanece até os dias de hoje, em que diversas pessoas tratam o futebol como um grande negócio (AIDAR; LEONCINI; OLIVEIRA, 2000; PRADO, 2002; FARIA, 2007; SPESSOTO, 2008; SCHARF, 2010)

Definido como um produto realizado por trabalhadores, utilizando espaços e equipamentos em competição entre adversários (SZYMANSKI; KUYPERS, 1999), o futebol caracteriza-se como negócio. Inúmeros autores corroboram com esta ideia, considerando este esporte uma indústria e um negócio (AIDAR; LEONCINI; OLIVEIRA, 2000; FERNANDES, 2000; SHACKLETON, 2000; PITTS; STOTLAR, 2002; PRADO, 2002; KERN; SÜSSMUTH, 2005; BARROS; LEACH, 2006; MAÇÃS, 2006; MYSKIW, 2006; ASCARI; GAGNEPAIN, 2007; FARIA, 2007; SPESSOTO, 2008; BARROS, GARCIA-DEL-BARRIO; LEACH, 2009; SAAR, 2009; DRUMMOND; ARAÚJO; SHIKIDA, 20I0; MALAGRINO, 20I I; ROCHA; BASTOS, 201 I; KAZNAR; GRAÇA FILHO, 20 I2). Apesar do objetivo prioritário dos clubes de futebol ser a obtenção de títulos (LEONCINI; SILVA, 2000; MYSKIW, 2006), Fernandes (2000) enfatiza a lucratividade como finalidade de qualquer organização e Soriano (2010) e Barros, Assaf e Earp (2010) completam afirmando que o desempenho financeiro deve estar conectado ao esportivo. Desta forma, passa a ser semelhante o desafio dos clubes esportivos e das empresas, que é implementar modernas técnicas administrativas, adotando métodos de gestão que permitam às mesmas serem competitivas (TACHIZAWA; FERREIRA; FORTUNA, 2004).

Atualmente grandes empresas atuam no mercado esportivo, desde patrocínios em camisas e fornecedores de materiais esportivos até Naming Rights. Sendo o esporte um fenômeno social e cultural, a participação de empresas comerciais e públicas fez o futebol se tornar um objeto de consumo (ROCHE, 2002; GRYNBERG, 2007; SOARES, 2007; MALAGRINO, 201 I ). Fernandes (2000) demonstra que no início dos anos 2000, a indústria do futebol movimentava $U \$ 2$ bilhões anuais no Brasil, representando 0,01\% do PIB (Produto Interno Bruto) nacional. Levando em consideração todos os esportes, em 1995 todo o volume de negócios esportivos no Brasil correspondia a I,5\% do PIB brasileiro e, em 2000, a participação 
esportiva no Produto Interno Bruto brasileiro passou a representar 2\% (KASZNAR; GRAÇA FILHO, 20 I2). Em estudo feito pela empresa de consultoria BDO (20 I I), apresentando dados sobre o mercado do futebol brasileiro, foi constatado que os clubes do Brasil movimentaram cerca de 2, 18 bilhões de reais em receitas no ano de 2010. A empresa Deloitte destaca o mercado mundial em relatório de 2011 , mostrando que as receitas somadas dos 20 clubes mais ricos do planeta superaram 4 bilhões de euros na temporada 20 I 0-20 I I. Em todo mundo, o futebol movimenta anualmente cerca de 250 bilhões de dólares e o Brasil, em relação a esses valores, representa menos de I\% (AIDAR; LEONCINI; OLIVEIRA, 2000; FERNANDES, 2000; LEONCINI; SILVA, 2005).

A pouca participação brasileira em todo esse mercado deve-se às grandes diferenças encontradas entre os clubes do Brasil e da Europa. Barros e Leach (2006) destacam que o comportamento esportivo e financeiro de um clube está relacionado com as qualidades administrativas de seu gestor, e por este motivo a distância financeira é justificada, uma vez que alguns dirigentes brasileiros ainda apresentam baixa qualificação profissional (MOCSÁNYI; BASTOS, 2005) e mentalidade amadora (FERNANDES, 2000; AZEVÊDO, 2002; CAMPOS; ROMAN, 2008; SPESSOTO, 2008), contrastando com os clubes europeus, que se encontram em um nível de evolução profissional muito superior (GONÇALVES; SILVA, 2007; MALAGRINO, 20I I), adotando medidas com ênfase em finanças e marketing (PRONI, 2000; SAAR, 2009). Para mais, Malagrino (20 I I ) ainda destaca que clubes desorganizados estão propensos a disputarem divisões inferiores, o que reforça a necessidade de profissionalizar a gestão.

Diversos estudos apresentam relações entre variáveis econômicas e o desempenho de equipes de futebol. Grande parte destes trabalhos avaliou e encontrou, a partir de métodos empíricos, correlações estatisticamente significativas entre salários e desempenho esportivo (SZYMANSKI; KUYPERS, 1999; FYNN; GUEST, 1998; ANDREFF, 2007; SHACKLETON, 2000; GUZMÁN; MORROW, 2007; KUPER; SZYMANSKI, 20I0; BARROS; GARCIA-DEL-BARRIO; EACH, 2009; DOUVIS; BARROS, 2009; BARROS; LEACH, 2007; BARROS; LEACH, 2006; SZYMANSKI, 2000; POZZI, 1999; GASPARETTO, 20 I2). Alguns trabalhos buscaram compreender a gestão financeira dos clubes através do mercado (OZAWA; CROSS; HENDERSON, 2004) e outras pesquisas foram feitas com os torcedores e o mercado dos clubes (BURAIMO; FORREST; SIMMONS, 2007). Porém, tais fatores em conjunto fazem com que o futebol seja considerado um grande negócio? $\bigcirc$ que realmente caracteriza uma atividade como grande negócio?

Segundo relatório elaborado pelo Ministério do Desenvolvimento, Indústria e Comércio Exterior (BRASIL, 2002) no Brasil, a Lei n 9.84I/99 define as micro e 
pequenas empresas em função do número de funcionários, independência do capital e receita bruta anual (BRASIL 2002). A análise das duas primeiras variáveis torna-se complexa, pois o tipo de serviço executado pelos clubes de futebol e o número de funcionários diferem-se das demais organizações. Porém, a comparação com os valores de receitas é possível e, como a lei prega o valor máximo de faturamento anual de $R \$$ I.200.000 (um milhão e duzentos mil reais) para as pequenas empresas, os grandes clubes de futebol não se encaixam nestes preceitos. No âmbito brasileiro não há definição das médias e grandes empresas em função do faturamento, porém tanto o Mercosul quando a União Europeia definem os valores para as médias organizações (BRASIL, 2002; COMISSÃO, 2003). Em relação ao mercado sul-americano, o faturamento anual para empresas voltadas para a indústria é de U\$ 20.000.000 (vinte milhões de dólares) anuais e para instituições de comércio e serviços U\$ 7.000 .000 (sete milhões de dólares) anuais (BRASIL, 2002). Os países europeus, que não fazem distinção ao tipo de operação das organizações, apresentam para as médias empresas o volume de negócios anual de €50.000.000 (cinquenta milhões de euros) (COMISSÃO, 2003).

Uma vez que os clubes de futebol são tratados como empresas, é imperativo que haja controle da folha salarial e entre receitas e despesas, fazendo com que o clube não acumule dívidas (LEONCINI; SILVA, 2005). Porém, essa não é a realidade de quase todos os clubes profissionais, visto que algumas das equipes que mais arrecadam no mundo apresentam grandes dívidas (QUEBRADOS, 20 I0). No Brasil, a situação financeira das equipes também mostra-se deficitária, visto que apenas 3 dos 20 principais clubes do país apresentaram superavit na temporada 2010 e 6 equipes em 201। (BDO, 201।; BDO, 2012)

Com essas dívidas, alguns investidores passam a desistir do objetivo de comprar ou administrar os clubes de futebol, uma vez que o mercado não se mostra rentável. Matarazzo (2007) define rentabilidade de uma empresa como o êxito econômico da mesma e a relação com o capital investido. Mesmo com os clubes de futebol tendo como objetivos estratégicos a maximização das receitas e redução dos custos (LEONCINI; SILVA, 2000; MYSKIW, 2006; MALAGRINO, 20 I I), eles também possuem como objetivo a conquista de títulos (LEONCINI; SILVA, 2000; MYSKIW, 2006). Entretanto, Soriano (20 I0) destaca que, além dos aspectos esportivos, as variáveis financeiras também devem ser consideradas. Desta forma, a ausência do retorno financeiro e o pequeno êxito econômico podem justificar o afastamento dos investidores.

A análise dos fatores internos e externos de uma organização, além do relacionamento entre essas variáveis, é de fundamental importância para o gerenciamento de negócios, uma vez que possibilita interação adequada entre os componentes 
(FREZATTI, 1999). Essa análise pode ser realizada através do Brand Value (Valor de Marca) e do Market Value (Valor de Mercado). As receitas de uma empresa também são um bom indicativo das operações que a mesma executa. Tanto o Brand Value, quanto o Market Value, representam parte do ativo intangível de uma organização. Uma vez que os ativos tangíveis representam os lucros normais de uma organização, a verdadeira criação de valor é gerada pelos ativos intangíveis (BORTOLUZZI; ENSSLIN; ENSSLIN, 20 I 0; PEREZ; FAMÁ, 2006). A avaliação dos aspectos tangíveis e intangíveis de uma empresa é fundamental para a sustentabilidade da mesma em longo prazo (BORTOLUZZI; ENSSLIN; ENSSLIN, 20I0).

Sendo assim, o presente estudo teve como objetivo testar a afirmação de que o futebol é financeiramente um grande negócio, fazendo um levantamento bibliográfico e, porteriormente, uma análise comparativa entre os mais valiosos clubes de futebol e as principais empresas brasileiras e mundiais, tendo como base os valores de Brand Value, Market Value e receitas operacionais.

\section{MÉTODOS}

presente estudo apresenta caráter bibliográfico com utilização de fontes secundárias e, na etapa comparativa entre empresas e clubes de futebol, adota abordagem empírico-analítica. Essa metodologia apresenta técnicas de coleta, tratamento e análise de dados (MARTINS, 1992).

Esta investigação utilizou pesquisas brasileiras e internacionais sobre o futebol, os negócios deste esporte, os clubes como empresas e os demais segmentos administrativos do futebol e das organizações. As pesquisas foram realizadas no metabuscador Periódicos Capes, além das bases de dados Emerald, SIRC Collection, Business Source Premier e EconPapers. Rankings de revistas econômicas como Forbes, Fortune 500 e Interbrand foram utilizados, assim como os principais relatórios feitos pelas empresas de consultoria esportiva Deloitte, Pluri Consultoria e BDO. As escolhas por estes rankings deveram-se à qualidade dos mesmos e ao conceito adquirido no mercado onde operam.

A moeda apresentada pelos rankings variava de acordo com o país ou mercado analisado. Desta forma, para a padronização de valores, adotou-se o Dólar Americano (US\$) como moeda de referência do estudo, considerando as relações US\$I,00 = R\$I,85 e €I,00 = US\$1,30, cotação do dia |6/I2/I I.

Os clubes e empresas selecionados para a pesquisa foram aqueles que se apresentavam como os mais valiosos em seus mercados, segundo os relatórios e rankings consultados (APPLE, 20 I0; BRASIL, 20 I 0; BDO, 20I I; BIGMAN, 20 I ; GLOBAL,

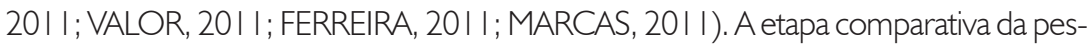
quisa avaliou os seguintes aspectos: Brand Value, Market Value e Receitas Operacionais. 
O Brand Value é o valor referente ao que a marca de determinado produto ou organização possui (NEL et al., 2009). Ele é mensurado a partir de uma análise detalhada, gerando um valor aproximado através de dados, como o mercado onde opera, a performance conquistada, o posicionamento, a concorrência, as estratégias futuras e os riscos operacionais (STOBART, 1994). É grande o poder que uma marca influencia no valor de uma empresa (AAKER, 2007; KELLER; MACHADO, 2006; DIAS, 2003; D'ALESSANDRO; OWENS, 2002), além de seu reconhecimento ser um fator chave para o sucesso das organizações (KOTLER; KELLER, 2006; HOOLEY; SAUNDERS; PIERCY, 2005). Para mais, o Brand Value também pode ser compreendido como um ativo independente (LOURO, 2000). Além disso, a relação do consumidor com o nome, o símbolo e o serviço prestado também influenciam no Brand Value (AAKER; JOACHIMSTHALER, 2000).

O Market Value é o valor gerado através da soma do capital de terceiros e acionistas avaliados a mercado (SANTOS; WATANABE, 2005). Analisando o mercado de capitais, ele é gerado ao multiplicar o preço de uma ação pelo número de ações desta organização que se encontram na bolsa de valores. Na prática, frequentemente utiliza-se o valor contábil do endividamento como substituto do seu valor de mercado (MARTINS, 200 I). Além disso, devido a alguns critérios subjetivos da contabilidade empresarial, muitas vezes o valor de mercado não coincide com o valor contábil (MÜLLER; TELÓ, 2003).

A análise do Market Value apresenta-se como complexa, uma vez que poucos são os clubes que apresentam capital aberto, tendo ações na bolsa de valores. Sendo assim, não foram inseridos na pesquisa apenas os clubes com capital aberto, visto que esses não são os clubes mais valiosos do mundo, apresentando-se, assim, como uma variável interveniente da pesquisa. No presente estudo foram utilizados os valores de mercado dos direitos dos atletas, baseado no fato de que através dos valores individuais é calculado o Market Value de uma mercadoria, no caso, os clubes (CIPOLLA, 2003). Isso é reforçado ao ver que em determinados tipos de organizações os preços de transferência funcionam como um excelente instrumento que tem como base o valor de mercado (CONSENZA; ALEGRÍA, 2004).

As receitas podem ser definidas como o valor monetário das operações realizadas durante um período (GITMAN, 1997). Enquanto as demais organizações obtêm sua arrecadação, prioritariamente, através de suas operações de vendas de produtos e prestação de serviços, os clubes de futebol apresentam como principais fontes de receitas os patrocínios, cotas televisivas, otimização da arena, arrecadação com bilheteria, ações de marketing e transferências de atletas, fatores que as organizações esportivas necessitam aprimorar ainda mais (GONÇALVES; CARVALHO, 2006; KERN; SÜSSMUTH, 2005; MYSKIW, 2006; CAMPOS; ROMAN, 2008; 
AIDAR, 20 I0; MALAGRINO, 20I I). Porém, ao contrário do que é feito no Brasil, as transferências de atletas deveriam representar aos clubes brasileiros as receitas não-operacionais, como fazem os clubes europeus (AIDAR, 20I0).

Para a realização da etapa comparativa, estas variáveis foram extraídas dos rankings consultados (APPLE, 20 I0; BRASIL, 20 I0; BDO, 20 I I; BIGMAN, 20 I I; GLOBAL, 20 I I; VALOR, 201 I; FERREIRA, 20 I I; MARCAS, 20 I I) e apresentados nas Tabelas I, 2, 3, 4, 5 e 6. Posteriormente, verificou-se a relação existente entre os mais valiosos de cada tabela, encontrando a proporção entre eles. Para mais, comparou-se, também, a proporção do valor que o clube mais valioso representa em relação à empresa de menor valor na tabela analisada. Estes cálculos foram realizados da seguinte forma: multiplica-se o valor (de marca, mercado ou receitas) do clube de futebol por 100 e divide-se este resultado pelo valor apresentado pela empresa a ser comparada no mesmo critério (valor de marca, mercado ou receitas), encontrando o percentual financeiro que o clube de futebol representa em relação à empresa, naquela variável.

\section{RESULTADOS}

Na Tabela I, estão apresentados o Brand Value (valor de marca) dos clubes na temporada 2010/20 I I e empresas mais valiosas do mundo no mesmo período.

Tabela I. Brand Value de equipes e empresas do Mundo em 2010/20I I - Bilhões de dólares (\$)

\begin{tabular}{cc}
\hline & Brand Value \\
\hline Clubes (US $\$$ ) & Empresas (US $\$$ ) \\
Manchester United - I,86 & Apple - 57,4 \\
Real Madrid - I,45 & Microsoft - 56,5 \\
Arsenal - I,19 & Coca-Cola - 55,4 \\
Bayern de Munique - I,03 & IBM - 43,0 \\
Barcelona - 0,975 & Google - 39,7 \\
Milan - 0,838 & McDonald's - 35,9 \\
Chelsea - 0,658 & General Electric - 33,7 \\
Juventus - 0,628 & Marlboro - 29, I
\end{tabular}

Fonte: Elaboração própria. Dados da Forbes.

Para a análise destes dados, foram comparados os valores de marca do Manchester United em relação ao valor da Apple, empresa com o maior valor de marca do mundo. Utilizando os $\cup \$ 57,4$ bilhões como um padrão de excelência, 
temos o Manchester United representando apenas 3,24\% deste valor, através do cálculo: U\$ I,86 * I 00 / U\$ 57,4 ₹ 3,24\% Para mais, ao utilizar a Marlboro como padão, o Manchester United, clube de futebol com o maior valor de marca do mundo, alcança, aproximadamente, 6,39\% deste valor.

$\mathrm{Na}$ Tabela 2, estão apresentados o Brand Value (valor de marca) dos clubes e empresas mais valiosos do Brasil em 2010.

Tabela 2. Brand Value de equipes e empresas do Brasil em 20 I 0. Bilhões de dólares (US\$)

\begin{tabular}{|c|c|}
\hline \multicolumn{2}{|c|}{ Brand Value } \\
\hline Clubes (US\$) & Empresas (US\$) \\
\hline Corinthians - 0,467 & Itaú - 13, I33 \\
\hline Flamengo - 0,373 & Bradesco - 7,370 \\
\hline São Paulo - 0,360 & Petrobras - 6,275 \\
\hline Palmeiras - 0,245 & Banco do Brasil - 6, I I3 \\
\hline Internacional - 0, I 50 & Skol - 3,934 \\
\hline Santos - 0,123 & Natura - 3,063 \\
\hline Grêmio - 0,121 & Brahma - 2,352 \\
\hline Vasco - 0,088 & Vale - I,436 \\
\hline Cruzeiro - 0,082 & Antartica - I,088 \\
\hline Atlético(MG) - 0,082 & Vivo - 0,919 \\
\hline Fluminense - 0,073 & Renner - 0,45। \\
\hline Botafogo - 0,049 & Lojas Americanas - 0,380 \\
\hline
\end{tabular}

Fonte: Elaboração própria. Dados de BDO e Interbrand.

Utilizando o mesmo cálculo, no Brasil a relação entre o valor de marca do clube mais valioso e a empresa de maior valor é de, aproximadamente, 3,56\%. Porém, a relação entre o Brand Value do Corinthians, clube com maior valor de marca, e a $12^{\mathrm{a}}$ empresa no ranking, as Lojas Americanas, é de, aproximadamente, 122,89\%, resultado que indica o clube com maior Brand Value. Deve-se destacar que o valor de marca do Corinthians também apresenta-se maior do que o valor da I I a organização no ranking, a Renner. Entretanto, é necessário ressaltar que este é o único clube brasileiro que apresenta Brand Value mais alto em comparação com alguma empresa do ranking.

$\mathrm{Na}$ Tabela 3, estão apresentados o Market Value (valor de mercado) dos clubes e empresas mais valiosos do mundo entre os anos 2010 e $201 \mathrm{I}$. 
Tabela 3. Market Value de clubes e empresas do Mundo em 20 I0/20 I I. Valores em bilhões de dólares (\$)

\begin{tabular}{cc}
\hline & Market Value \\
\hline Clubes (US\$) & Empresas (US\$) \\
Barcelona - 0,81 & Exxon Mobil - 323,717 \\
Real Madrid - 0,70 & Microsoft Corp - 270,636 \\
Manchester City - 0,58 & Wal-Mart Stores - 203,654 \\
Chelsea - 0,57 & Google Inc'A' - 196,70 I \\
Manchester United - 0,55 & Apple Inc - 189,800 \\
\hline
\end{tabular}

Fonte: Elaboração própria. Dados de Pluri Consultoria/Ferreira e Forbes.

Com os resultados de Market Value apresentados, é possível constatar ainda mais a diferença financeira entre clubes de futebol e empresas. A proporção existente do Market Value entre o clube mais valioso, Barcelona, e a empresa de maior valor de mercado, Exxon Mobil, é de, aproximadamente, 0,25\% (U\$ 0,8। * 100 / U\$ $323,717 \approx 0,25 \%)$. Não muito distante, a proporção do valor do Barcelona com a $5^{a}$ empresa, Apple Inc., é de, aproximadamente, 0,43\%.

Na Tabela 4, estão apresentados o Market Value (valor de mercado) dos clubes e empresas mais valiosos do Brasil em 2010.

Tabela 4. Market Value de clubes e empresas do Mundo em 2010.

Valores em bilhões de dólares (\$)

\begin{tabular}{|c|c|}
\hline \multicolumn{2}{|c|}{ Market Value } \\
\hline Clubes (US\$) & Empresas (US\$) \\
\hline Santos - 0,186 & Petrobras - 228,2 \\
\hline São Paulo - 0, 122 & Vale - 166,2 \\
\hline Internacional - 0, 106 & Itaú - 96,4 \\
\hline Corinthians - 0,093 & Ambev - 86,6 \\
\hline Vasco - 0,086 & Bradesco $-67,0$ \\
\hline Flamengo - 0,081 & Banco do Brasil - 53,9 \\
\hline Fluminense - 0,076 & Santander Brasil - 5I,9 \\
\hline Grêmio - 0,076 & OGX Petróleo - 38,8 \\
\hline Atlético-MG - 0,064 & Itaúsa - 35,9 \\
\hline Botafogo - 0,06। & Companhia Siderúrgica Nacional - 23,3 \\
\hline
\end{tabular}

Fonte: Elaboração Própria. Dados de BDO e Economática/Folha de São Paulo. 
No Brasil, a disparidade econômica é ainda maior entre clubes de futebol e as demais organizações, uma vez que o valor de mercado do Santos, através do cálculo anteriormente apresentado, representa, aproximadamente, 0,08\% do Market Value da Petrobrás. Entre o mesmo clube e a Companhia Siderúrgica Nacional, décima empresa em valor de mercado, o clube de futebol representa, financeiramente, aproximadamente 0,80\%.

$\mathrm{Na}$ Tabela 5, estão apresentadas as receitas dos principais clubes em 2010/20 I I e empresas do mundo nos mesmos anos.

Tabela 5. Receitas Operacionais de clubes e empresas do Mundo em 2010/20 I I.

Valores em bilhões de dólares (\$)

\begin{tabular}{|c|c|}
\hline \multicolumn{2}{|c|}{ Receitas } \\
\hline Clubes (US\$) & Empresas (US\$) \\
\hline Real Madrid - 0,57। & Wallmart - 408,0 \\
\hline Barcelona - 0,5 I7 & Shell - 378, 152 \\
\hline Manchester United - 0,455 & Exxon Mobil - 354,674 \\
\hline Bayern de Munique - 0,4I2 & British Petroleum - 308,928 \\
\hline Arsenal - 0,356 & Sinopec - 273,422 \\
\hline Chelsea - 0,333 & China National Petroleum - 240, 192 \\
\hline Milan - 0,307 & State Grid - 226.294 \\
\hline Liverpool - 0,292 & Toyota Motor - 221,760 \\
\hline Internazionale - 0,292 & Japan PostHoldings - 203,958 \\
\hline Juventus - 0,267 & Chevron - 196,337 \\
\hline
\end{tabular}

Fonte: Elaboração própria. Dados de Deloitte e Global 500/Fortune/CNNMONEY.

Nas receitas operacionais, que dizem respeito aos valores que a organização capta durante o período de um ano, a relação existente entre o clube que mais arrecadou em 2010/201 I, o Real Madrid, e a empresa com maior captação de recursos no mesmo período, a Wallmart, é de, aproximadamente, 0, I 4\%. Comparando o volume de receitas do Real Madrid com a Chevron, $10^{a}$ empresa em arrecadação, a relação existente é de, aproximadamente, 0,29\%, através do cálculo proposto pelo estudo.

Na Tabela 6, estão apresentadas as receitas dos principais clubes e empresas do Brasil em 2010. 
Tabela 6. Receitas Operacionais de clubes e empresas do Brasil em 2010. Valores em bilhões de dólares (\$)

\begin{tabular}{|c|c|}
\hline \multicolumn{2}{|c|}{ Receitas } \\
\hline Clubes (US\$) & Empresas (US\$) \\
\hline Corinthians - 0,1 I5 & Petrobras - 91,87 \\
\hline Internacional - 0,109 & Itaúsa - 57,86 \\
\hline São Paulo - 0, 106 & Bradesco - 5l,6l \\
\hline Palmeiras - 0,080 & Banco do Brasil - 48.12 \\
\hline Flamengo - 0,070 & Vale - 23,31 \\
\hline Santos - 0,063 & Ultrapar Holdings - I8,06 \\
\hline Grêmio - 0,062 & JBS - 17,16 \\
\hline
\end{tabular}

Fonte: Elaboração própria. Dados de BDO, e Fortune/O Globo.

No Brasil, as receitas operacionais do Corinthians representaram, aproximadamente, 0,13\% do volume de arrecadação da Petrobrás e, comparando a arrecadação da mesma equipe com a JBS, $7^{\mathrm{a}}$ empresa nacional em receitas, a relação é de, aproximadamente, 0,67\%.

Como é possível perceber nas tabelas anteriormente apresentadas, a diferença entre os valores é discrepante comparando-se clubes e empresas, tanto no mercado brasileiro, quanto em todo o mundo. Ao comparar Market Value e Receitas Operacionais, os valores alcançados pelos clubes não representam I \% dos valores das empresas. Ao fazer a relação utilizando-se Brand Value como referência, os valores apresentados pelos clubes representaram entre 3\% e 7\% dos valores de marca das empresas. A única exceção ocorreu no Brasil, em que o clube de maior Brand Value possui valor de marca maior que o da $12^{\mathrm{a}}$ organização nesta variável. Essa análise destaca, então, a distância econômica entre os clubes de futebol e as empresas dos demais segmentos.

\section{DISCUSSÃO}

Através dos resultados, foi possível constatar distância considerável entre os valores apresentados pelos principais clubes e as demais empresas, nas três variáveis analisadas, tanto no mercado brasileiro, quanto no mundial. Sendo assim, esses dados poderiam responder o objetivo do estudo, que foi testar a afirmação de que o futebol é financeiramente um grande negócio, afirmando que, atualmente, o mesmo apresenta-se economicamente muito longe das grandes organizações mundiais. Porém, utilizando as definições brasileira, sul-americana e europeia de micros, pequenas e médias empresas, os clubes de futebol devem ser considerados grandes instituições ao avaliar o volume do faturamento destas agremiações. 
Inicialmente, é necessário ressaltar a diferença entre operações realizadas pelos clubes de futebol e as demais atividades empresariais, uma vez que, estando em mercados completamente diferentes, torna-se complexa a comparação entre organizações. No topo dos rankings, encontram-se empresas petrolíferas, bancos e de aparelhos eletrônicos. $\bigcirc$ volume de atividades dessas organizações é muito superior ao dos clubes de futebol, o que dificulta a análise, porém não inviabiliza a comparação das mesmas, uma vez que, nos rankings apresentados pela Forbes, Fortune 500 e Interbrand, também são encontradas organizações de diferentes ramos. Mello, Amorim e Bandeira (2008) corroboram esta ideia ao afirmar que existe a possibilidade de comparação entre organizações de diferentes setores ou níveis de investimento, visto que não apenas o indicador de faturamento bruto representa necessariamente um melhor desempenho operacional. Todavia, como o presente estudo não avaliou o desempenho operacional, mas apenas os dados financeiros, os valores que os clubes representam, menos de $1 \%$ dos valores das empresas em determinadas variáveis, tornam-se pequenos negócios financeiros em comparação às grandes organizações, utilizando como referência Brand Value, Market Value e receitas operacionais.

Como os grandes clubes de futebol não possuem, atualmente, o patamar financeiro das demais organizações, estas equipes devem, então, serem analisadas em relação aos outros esportes para terem a dimensão relativa com o mercado onde atuam. Em ranking feito pela Forbes, em que estão apresentadas as 50 marcas esportivas mais valiosas do mundo, apenas 8 clubes de futebol estão inseridos e, apesar de no topo do ranking estar um clube de futebol, o Manchester United, o futebol representa apenas $16 \%$ do total, valor muito baixo se comparado aos $64 \%$ que o futebol americano alcançou no mesmo ranking, com 32 equipes entre as 50 primeiras (THE WORLD'S, 20 I I).

Apesar dos resultados encontrados apresentarem uma diferença significativa entre os valores dos clubes de futebol e das grandes empresas mundiais, deve-se destacar que tais variáveis analisadas têm algumas peculiaridades, isto porque, tanto - Market Value, quanto o Brand Value, apresentam variações muito drásticas que dificilmente são mensuráveis. $\bigcirc$ desempenho de uma equipe pode alterar as duas variáveis, porém essa não seria uma justificativa tão relevante, visto que qualquer tipo de insucesso também alteraria esses dois valores em outras organizações. Porém, algumas situações não planejadas podem ocorrer com maior facilidade com os clubes de futebol que alterassem drasticamente o Market Value. Situações em que o montante da transferência pode ser diferente do valor anteriormente estabelecido, como em liberações de atletas com valores muito abaixo do valor de mercado e, até mesmo, a custo zero, devido a casos de indisciplina, baixo rendimento individual 
e, também, lesões, refletirão diretamente nos resultados econômicos (COSENZA; ALEGRÍA, 2004). Sendo assim, a análise destas variáveis reflete uma situação momentânea, podendo ser sensivelmente modificada de uma temporada para a outra.

Outro importante fator na comparação entre as organizações diz respeito às características do mercado, como as mercadorias, consumidores e o ativo financeiro. Estes três pontos diferem totalmente o futebol de outros mercados, visto que, no caso deste esporte, são representados por jogadores, torcedores e pelo jogo, respectivamente (GONÇALVES; CARVALHO, 2006).

Como os atletas representam as mercadorias (GONÇALVES; CARVALHO, 2006) e estas mercadorias são extremamente valorizadas, a venda de um jogador pode acarretar em queda de desempenho esportivo, que, consequentemente, pode gerar inicialmente um prejuízo técnico, e em longo prazo pode tornar-se um prejuízo financeiro.

Em relação aos torcedores, o futebol não segue a lógica dos demais mercados. Por apresentarem fidelidade incondicional, os clubes consideram quase inexistentes o risco de perder seu consumidor (MAZZEI; BASTOS, 20I2). Isso se deve ao fato de que raramente um clube consegue conquistar o consumidor da concorrência, uma vez que a concorrência é justamente o clube rival. Sendo assim, o mercado é, de certa forma, restrito ao seu país, tendo como grande expectativa do clube fazer com que as futuras gerações passem a torcer por sua equipe. Sabendo, então, que não é possível atingir todos os consumidores, torna-se necessário posicionar seus produtos para obter vantagens competitivas em relação aos concorrentes (SILVA et al., 2006). Porém, a alternativa mais viável para o aumento das receitas talvez seja conseguir que aqueles atuais torcedores aumentem seu poder de consumo (SORIANO, 20I0). Para acompanhar esse desenvolvimento deve-se levar em consideração o percentual de mercado, a evolução de mercado e velocidade de vendas (MELLO; AMORIM; BANDEIRA, 2008).

Sobre o jogo propriamente dito, visto que este representa um ativo financeiro dos clubes de futebol, pode-se constatar a grande diferença entre clubes e empresas. No caso das empresas, o ativo financeiro tem por objetivo ser lucrativo (FERNANDES, 2000; LEONCINI; SILVA, 2005; SORIANO, 20 I0) e, nas grandes organizações, este objetivo é alcançado. No caso do futebol, principalmente em se tratando dos clubes brasileiros, esta situação não é uma realidade, pois o faturamento com os jogos representam apenas 1 1\% das receitas dos clubes no Brasil, baixo valor se comparado à média europeia, 26\%, chegando a alcançar 39\% em alguns clubes como o Manchester United (AIDAR, 2010). No futebol brasileiro isso se deve, prioritariamente, à baixa média de espectadores por partida (BORTOLUZZO; IAROPOLLI; MACHADO, 20 I I). 
Desta forma, as diferentes características do mercado esportivo em relação ao restante do meio empresarial reforçam a necessidade de comparação dos clubes de futebol com outras agremiações da indústria dos esportes, uma vez que a distância financeira existente entre grandes clubes e grandes empresas foi constatada.

Este estudo não esgota as possibilidades de investigação e não se propõe a finalizar a discussão sobre esta temática. É necessário ressaltar que o presente artigo limitou-se a uma pequena parcela do mundo do futebol, que são as grandes equipes. Desta forma, alguns questionamentos fogem do escopo deste artigo, mas apresentam-se como relevantes para a elaboração de novas pesquisas sobre as finanças dos clubes esportivos e as demais organizações. Onde estão situados os pequenos e médios clubes de futebol em um contexto empresarial? $\bigcirc$ futebol é um grande negócio para quem? Quem são os agentes que se beneficiam economicamente dos esportes? Quais outras variáveis são possíveis de realizar na comparação entre clubes de futebol e as demais organizações? $\bigcirc$ marketing esportivo poderia auxiliar na redução da diferença econômica entre os clubes esportivos e as demais organizações? Qual tipo de organização pode ser comparado às agremiações esportivas? Os esportes, hoje incluídos na indústria do entretenimento, apresentam qual posicionamento perante este mercado? Os esportes poderiam se encaixar na categoria de Comércio e Serviços? Os esportes poderiam se encaixar na categoria de Indústria? Qual é a representatividade econômica do futebol em comparação aos demais esportes? Qual é o relacionamento existente entre as principais empresas e os grandes clubes mundiais? Quais são os motivos que aproximam ou afastam as grandes organizações das equipes esportivas? Como mensurar economicamente o relacionamento entre essas empresas e os clubes de futebol? Qual a relação existente entre os aspectos sociais e políticos e as variáveis econômicas dos clubes de futebol? Estas questões, entre várias outras, poderão ampliar a discussão sobre os aspectos econômicos e financeiros dos clubes de futebol e dos esportes como um todo.

Por fim, os achados desse estudo reforçam a ideia de que o futebol é um negócio, porém possui representatividade financeira muito menor do que comumente é considerado. Sendo assim, torna-se de grande importância a realização de investigações semelhantes, utilizando variáveis alternativas às trabalhadas neste artigo, com o objetivo de comparar ainda mais profundamente a indústria do futebol com os demais ramos empresariais. Estimulam-se, também, pesquisas com os demais esportes para uma melhor caracterização dos mercados esportivos.

\section{CONCLUSÃO}

Ao término do presente estudo, é possível concluir, com os resultados apresentados, que o futebol é um grande negócio, pois movimenta valores superiores 
aos das micro, pequenas e médias empresas. Entretanto, é necessário ressaltar a baixa representatividade financeira que os mais valiosos clubes de futebol possuem perante o mercado econômico mundial, uma vez que é grande a diferença de valores entre este esporte e as grandes atividades empresariais do mundo. Em última análise, esta investigação tem como propósito estimular novos estudos sobre a temática econômica e financeira do futebol e dos demais esportes.

\section{Football as a Business: One Financial Comparison with Other Segments}

ABSTRACT: Football is considered a big business since the beginning of the last century. Although many authors try to define this statement, the present study demonstrated an interest in investigating it through another perspective, aiming to compare the largest sports clubs with leading companies in other business sectors using financial data. Initially, it was adopted as the method literature review of secondary sources. Subsequently, steps were conducted empirical-analytic techniques through collection, processing and analysis of data, with comparisons between the values found. Football presented itself as a big business because the values of revenues, but when compared to Brand Value, Market Value and Revenues with leading companies, the research showed that as a result the vast economic gap between the football clubs and largest companies in Brazil and the world, exposing thereby the economic small portion that represents this sport in relation to biggest organizations worldwide. KEYWORDS: Football; Revenues; Brand Value; Market Value.

\section{Fútbol como negocio: una comparación financiera con otros segmentos}

RESUMEN: El fútbol es considerado como un gran negocio desde el principio del siglo pasado. Aunque muchos autores tratan de definir esta declaración, el presente estudio demostró un interés en la investigación a través de otro punto de vista, con el objetivo de comparar los grandes clubes deportivos con empresas líderes en otros sectores empresariales, utilizando los datos financieros. En este artículo se aprobó como método una revisión bibliográfica de fuentes secundarias. Sin embargo, los pasos siguientes se caracterizaron como empírico-analíticos a través de las técnicas de recolección, procesamiento y análisis de datos, con comparaciones entre los valores encontrados. El fútbol se presentó como un gran negocio debido a que los ingresos totales, pero si se compara el valor de marca, valor de mercado y los ingresos con empresas líderes, la investigación mostró como resultado la enorme brecha económica entre los clubes de fútbol y las mayores organizaciones de Brasil y del exterior, exponiendo así la parte económica reducida que representa este deporte en relación con las organizaciones más importantes del mundo.

PALABRAS CLAVE: Fútbol; ingresos; valor de marca; valor de mercado. 


\section{REFERÊNCIAS}

AAKER, D. A. Construindo marcas fortes. Porto Alegre: Bookman, 2007. .; JOACHIMSTHALER, E. Brand leadership. New York: Free, 2000.

AIDAR, A. C. K. O torcedor como cliente: uma solução para aumentar as receitas dos clubes brasileiros. Cadernos FGV Projetos, Rio de Janeiro, v. I, n. 13, 2010.

.; LEONCINI, M. P.; OLIVEIRA, J. J. A nova gestão do futebol. Rio de Janeiro: Ed. da FGV, 2000.

ANDREFF, W. French football: a financial crisis rooted in weak governance. Journal of Sports Economics, v. 8, n. 6, p. 652-661, 2007.

APPLE E MICROSOFT SÃO AS MARCAS MAIS VALIOSAS DO MUNDO, SEGUNDO A FORBES. Globo.com. 29 de jul. 20 I0. GI. Tecnologia e games. Disponível em: <http:// gl .globo.com/tecnologia/noticia/20 I 0/07/apple-e-microsoft-sao-marcas-mais-valiosas-do-mundo-segundo-forbes.html>. Acesso em: 10 ago. 2010.

ASCARI, G.; GAGNEPAIN, P. Evaluating rent dissipation in the spanish football industry. Journal of Sports Economics, v. 8, n. 5, p. 468-490, 2007.

AZEVÊDO, P. H. A administração dos clubes de futebol profissional no Distrito Federal em face à nova legislação esportiva brasileira. 2002. I 83 f. Dissertação (Mestrado em Administração) - Faculdade de Estudos Sociais Aplicados, Universidade de Brasília, Brasília, 2002.

BARROS, C. P.; ASSAF, A.; EARP, F. Brazilian football league technical efficiency: a Simar and Wilson approach. Journal of Sports Economics, vol. II , n. 6, p 64I-65I, 2010.

BARROS, C. P.; GARCIA-DEL-BARRIO, P.; LEACH, S. Analyzing the Technical Efficiency of the Spanish Football League First Division with a Random Frontier Model. Applied Economics, vol. 45, n. 25, p. 3239-3247, 2009.

BARROS, C. P.; LEACH, S. Analyzing the Performance of the English F.A. Premier League With an Econometric Frontier Model. Journal of Sports Economics, vol. 7, n. 4, p. 39I-407, 2006.

BARROS, C. P.; LEACH, S. Technical efficiency in the English Football Association Premier League with a stochastic cost frontier. Applied Economics Letters, v. I4, n. I0, p. 73 I-741 I, 2007.

BDO. Indústria do esporte: finanças dos clubes de futebol do Brasil em 2010 . maio 201 I . Esportes. Disponível em: < http://www.bdobrazil.com.br/pt/analises/esporte/Finan\%C3\%A7as\%20 dos\%20Clubes\%20Brasileiros.pdf > . Acesso em: 15 nov. 201 I.

BDO. Finanças dos clubes de futebol do Brasil em 20 II. maio 20 I2. Especiais. Disponível em: <http://mwn.estadao.com.br/especiais/20 I2/05/financasclubes.pdf>. Acesso em: 20 ago. 20 I2. 
BIGMAN, D. The world's most valuable soccer teams. Forbes, New York, abr. 20। I. Disponível em: <http://www.forbes.com/sites/sportsmoney/20 I I/04/20/the-worlds-most-valuable-soccer-teams/>. Acesso em: 15 nov. 201 I.

BORTOLUZZI, S. C.; ENSSLIN, S. R.; ENSSLIN, L. Avaliação de desempenho dos aspectos tangíveis e intangíveis da área de mercado: estudo de caso de uma média empresa industrial. Revista Brasileira de Gestão de Negócios, São Paulo, v. 12, n. 37, 2010.

BORTOLUZZO, A. B.; IAROPOLI, P. T.; MACHADO, S. J. Demand for brazilian soccer: a censored model approach. Insper Working Paper, v. 237, p. I- 18, 201 I.

BRASIL. Ministério do Desenvolvimento, Indústria e Comércio Exterior. Secretaria do Desenvolvimento da Produção. Micro, pequenas e médias empresas: definições e estatísticas internacionais. Brasília: 2002.

BRASIL TEM SETE EMPRESAS ENTRE AS 500 MAIORES DO MUNDO, DIZ "FORTUNE". O Globo, Rio de Janeiro, 8 jul. 2010 . Economia.

BURAIMO, B.; FORREST, D.; SIMMONS, R. Freedom of entry, market size, and competitive outcome: evidence from english soccer. Southern Economic Journal, Chapel Hill, v.74, n. I , 2007.

CAMPOS, L. C. F; ROMAN, E. P. Diferenças de planejamento e administração de clubes de futebol da Europa e do Brasil. Revista Mineira de Educação Física, Viçosa, v. I6, n. I, p. 50-63, 2008.

CIPOLLA, F. P. Valor de mercado, preço de mercado e o conceito de mais valia extraordinária. Revista da Sociedade Brasileira de Economia Política, Rio de Janeiro, v. I , n. I 2, 2003.

COMISSÃO DAS COMUNIDADES EUROPÉIAS. Recomendação da Comissão de 6 de maio de 2003 relativa à definição de micro, pequenas e médias empresas. Jornal Oficial da União Européia, v. 1422, n. C, 2003.

COSENZA, J. P.; ALEGRÍA, A. I. Z. Considerações sobre os preços de transferências a partir de uma perspectiva de gestão empresaria. Caderno de Pesquisas em Administração, São Paulo, v. II, n. 3, 2004.

D'ALESSANDRO, D.; OWENS, M. Guerra das marcas: 10 regras para desenvolver uma marca vitoriosa. São Paulo: Pearson Education do Brasil, 2002.

DIAS, S. R. Gestão de marketing. São Paulo: Saraiva, 2003.

DOUVIS, I.; BARROS, C. P. Comparative analysis of football efficiency among two small European countries: Portugal and Greece. International Journal of Sports Management and Marketing, v. 6, n. 2, p. 183-199, 2009.

DRUMMOND, L; ARAÚJO, A. F; SHIKIDA, C. D. Campeonato Brasileiro de Futebol e balanço competitivo: uma análise do período 197| -2009. Revista Brasileira de Futebol, Viçosa, v. 3, n. 2, p. 73-87, jul./dez. 2010. 
FARIA, P. C. N. Marketing futebol clube: um estudo de múltiplos casos sobre associação de imagem a envolvimento e à identidade em clubes de futebol. 2007. 228 f. Dissertação (Mestrado em Administração) - Faculdade de Ciências Econômicas, Universidade Federal de Minas Gerais, Belo Horizonte, 2007.

FERNANDES, L. F. F. A gestão dos clubes de futebol como clube empresa: estratégias de negócio. 2000. Dissertação (Mestrado em Administração) - Faculdade de Administração, Universidade Federal do Rio Grande do Sul, Porto Alegre, 2000.

FERREIRA, F. P. O valor de jogadores, times e campeonatos. Curitiba: Pluri Consultoria, 201 I . ( I Painel Pluri Futebol 20 I I). Disponível em: < http://www.pluriconsultoria.com.br/uploads/ relatorios/PAINEL\%20PLURI\%20FUTEBOL\%2020 I | \%20-\%20pt I .pdf>. Acesso em: I 2 dez. 2011 .

FREZATTI, F. A decomposição do MVA® (Market Value Added) na análise de valor da empresa. Revista de Administração, São Paulo, v. 34, n. 3, p. 32-43, jul./set. 1999.

FYNN, A.; GUEST, L. For love or money: Manchester United and England - the business of winning? Londres: Macmillan, 1998.

GASPARETTO, T. M. Relationship between wages and sports performance. The Empirical Economics Letters, v. I I, n. 9, p. 943-949, sept. 2012.

GITMAN, L. J. Princípios de administração financeira. 7. ed. São Paulo: Harbra, 1997.

GLOBAL 500. CNNMoney: a service of CNN, Fortune \& Money. 201 I. Disponível em: <http://money.cnn.com/magazines/fortune/global500/20 I I/full_list/>. Acesso em: I 0 ago. 20 I I .

GONÇALVES, J. C. S.; CARVALHO, C. A. A mercantilização do futebol brasileiro: instrumentos, avanços e resistências. Cadernos EBAPE. BR, Rio de Janeiro, v. 4, n. 2, p. I-27, 2006.

GONÇALVES, J. C. S.; SILVA, C. E. "Empresarização" e controle: o caso do Figueirense Futebol Clube. Cadernos EBAPE.BR, Rio de Janeiro, v. 5, n. 3, p. I-16, 2007.

GRYNBERG, C. O impacto do patrocínio esportivo no consumidor: um modelo para mensuração de sua efetividade (dissertação de Mestrado) Administração pela Pontifícia Universidade Católica do Rio de Janeiro. Rio de Janeiro: 2007.

GUZMÁN, I.; MORROW, S. Measuring efficiency and productivity in professional football teams: evidence from the English Premier League. Central European Journal of Operations Research, v. 15, n. 4, p. 309-328, 2007.

HOOLEY, G. J.; SAUNDERS, J. A.; PIERCY, N. F. Estratégia de marketing e posicionamento competitivo. São Paulo: Pearson Prentice Hall, 2005.

KASZNAR, I.; GRAÇA FILHO, A. S. A indústria do esporte no Brasil: economia, PIB - produto interno bruto, empregos e evolução dinâmica. São Paulo: M. Books, 2012. 
KELLER, K. L.; MACHADO, M. Gestão estratégica de marcas. São Paulo: Pearson Prentice Hall, 2006.

KERN, M.; SÜSSMUTH, B. Managerial efficiency in German Top League: an econometric analysis of club performances on and off the pitch. German Economic Review, Stuttgart, v. 6, n. 4, p. 485-506, 2005.

KOTLER, P.; KELLER, K. L. Administração de marketing. 2. ed. São Paulo: Pearson Prentice Hall, 2006.

KUPER, S.; SZYMANSKI, S. Soccernomics: por que a Inglaterra perde, a Alemanha e o Brasil ganham, e os Estados Unidos, o Japão, a Austrália, a Turquia - e até mesmo o Iraque - podem se tornar os reis do esporte mais popular do mundo. Rio de Janeiro: Tinta Negra, 2010.

LEONCINI, M. P.; SILVA, M. T. Entendendo o futebol como um negócio: um estudo exploratório. Gestão e Produção, São Carlos, v. 12, n. I, p. II-23, 2005.

LEONCINI, M. P.; SILVA, M. T. A Gestão estratégica de clubes de futebol vista através do caso Manchester United. In: ENCONTRO NACIONAL DE ENGENHARIA DE PRODUÇÃO - ENEGEP, 20., 2000. São Paulo. Anais... São Paulo, 2000.

LOURO, M. J. S. Modelos de avaliação de marca. Revista de Administraçãa de Empresas, São Paulo, v. 40, n. 2, 2000.

MAÇÃS, V. M. O. O director desportivo nas organizações do futebol em Portugal: caracterização da actividade dos gestores de desporto nos clubes de futebol profissional e não profissional. 2006. Tese (Doutorado em Educação Física e Desporto) - Universidade Trás-os-Montes e Alto Douro, Vila Real, 2006.

MALAGRINO, F. A. F. A gestão das marcas dos clubes de futebol: como o marketing esportivo potencializa o consumo do torcedor. 201 I . Dissertação (Mestrado em Administração) - Pontifícia Universidade Católica de São Paulo, São Paulo, 201 I.

MARCAS BRASILEIRAS MAIS VALIOSAS $201 \mathrm{I}$ : a nova era da cidadania corporativa. Interbrand do Brasil. 20I I. Disponível em: <http://www.interbrand.com/Libraries/Branding_Studies/ Marcas_brasileiras_mais_valiosas_201 l.sflb.ashx>. Acesso em: 25 ago. 201 l .

MARTINS, E. Avaliação de empresas: da mensuração contábil à econômica. São Paulo: Atlas, 200 I .

MARTINS, G. A. Manual para elaboração de monografias e dissertações. São Paulo: Atlas, 1992.

MATARAZZO, D. C. Análise financeira de balanços: abordagem básica e gerencial. 6. ed. São Paulo: Atlas, 2007.

MAZZEI, L. C.; BASTOS, F. C. Gestão do esporte no Brasil: desafios e perspectivas. São Paulo: Ícone, 2012.

MELLO, L. C. B. B.; AMORIM, S. R. L.; BANDEIRA, R. A. M. Um sistema de indicadores para comparação entre organizações: o caso das pequenas e médias empresas de construção civil. Gestão \& Produção, São Carlos, v. I 5, n. 2, p. 26I-274, 2008. 
MOCSÁNYI, V.; BASTOS, F. C. Gestão de pessoas na administração esportiva: considerações sobre os principais processos. Revista Mackenzie de Educação Física e Esporte, São Paulo, v. 4, n. 4, p. 55-69, 2005.

MÜLLER, A. N.; TELÓ, A. R. Modelos de avaliação de empresas. Revista da FAE, v. 6, n. I , 2003.

MYSKIW, M. Marketing esportivo no futebol: um olhar à luz do paradigma do marketing de relacionamento. 2006. Dissertação (Mestrado em Administração) - Centro de Ciências Sociais e Humanas, Universidade Federal de Santa Maria, Santa Maria, 2006.

NELL, J. D. W. et al. A comparative study of customer-based brand equit across selected South Afrivcan hotels. International Retail and Marketing Review, v. 5, n. I, p. I 5-24, 2009.

OZAWA, T.; CROSS, J.; HENDERSON, S. Market orientation and financial performance of English professional football clubs. Journal of Targeting, Measurement and Analysis for Marketing, v. I3, n. I, 2004.

PEREZ, M. M.; FAMÁ, R. Ativos intangíveis e o desempenho empresarial. Revista Contabilidade \& Finanças, São Paulo, v. 17, n. 40, p. 7-24, 2006.

PITTS, B. G.; STOTLAR, D. K. Fundamentos de marketing esportivo. São Paulo: Phorte, 2002.

POZZI, L. F. Futebol empresa. In: COSTA, M. R. et al. Futebol: espetáculo do século. São Paulo: Musa, 1999.

PRADO, F. Futebol: qual é o negócio. Rio de Janeiro: Ed. da FGV, 2002.

PRONI, N. W. A metamorfose do futebol. São Paulo: Ed. da Unicamp, 2000.

QUEBRADOS! os clubes mais endividados da Europa. Brave MensWorld, 8 jul. 2010. Disponível em: <http://www.bravemw.com.br/blog/2010/07/quebrados-os-clubes-mais-endividados-da-europa/>. Acesso em: 10 ago. 2010.

ROCHA, C. M.; BASTOS, F. C. Gestão do esporte: definindo a área. Revista Brasileira de Educação Física e Esporte, São Paulo, v. 25, n. esp., p. 91-103, dez. 201 I.

ROCHE, F. P. Gestão desportiva: planejamento estratégico nas organizações desportivas. 2. ed. Porto Alegre: Artmed, 2003.

SAAR, J. F. As estratégias de comunicação da Liga Futsal 2008: comunicação e negócios versus futebol arte. 2009. Dissertação (Mestrado em Comunicação Social) - Universidade Metodista de São Paulo, São Bernardo do Campo, 2009.

SANTOS, J. O.; WATANABE, R. Uma análise da correlação entre EVA® e o MVA® no contexto das empresas brasileiras de capital aberto. Caderno de Pesquisas em Administração, São Paulo, v. I 2, n. I, 2005.

SCHARF, E. R. O patrocínio do futebol como ferramenta do marketing esportivo para a construção do brand awareness. Revista Economia e Gestão, v. I0, n. 23, 2010. 
SHACKLETON, J. R. Football as a business. Football Studies, v. 3, n. I, p. 80-89, 2000.

SILVA, H. H. et al. Planejamento estratégico de marketing. Rio de Janeiro: Ed. da FGV, 2006.

SOARES, M. L. A miopia do marketing esportivo dos clubes de futebol no Brasil: proposta de um modelo de gestão de marketing esportivo para os clubes brasileiros. 2007. 338 f. Tese (Doutorado em Administração) - Faculdade de Economia, Administração e Contabilidade, Universidade de São Paulo, São Paulo, 2007.

SORIANO, F. A bola não entra por acaso: estratégias inovadoras de gestão inspiradas no mundo do futebol. São Paulo: Larousse, 2010.

SPESSOTO, R. E. N. Futebol profissional e administração profissional: da prática amadorista à gestão competitiva. 2008. Dissertação (Mestrado em Educação Física) - Faculdade de Educação Física, Universidade de Brasília, Brasília, 2008.

STOBART, P. Brand power. Londres: Macmillan, 1994.

STOLEN, T. et al. Physiology of soccer: an update. Sports Medicine, Auckland, v. 35, n. 6, p. 50l-536, 2005.

SZYMANSKI, S. A market test for discrimination in the English Professional Soccer Leagues. Journal of Political Economy, v. 108, n. 3, p. 590-603, 2000.

Group, 1999.

; KUYPERS, T. Winners and losers: the business strategy of football. Londres: Penguin

TACHIZAWA, T.; FERREIRA, V. C. P.; FORTUNA, A. A. M. Gestão com pessoas: uma abordagem aplicada às estratégias de negócios. Rio de Janeiro: Ed. da FGV, 2004.

THE WORLD'S MOST VALUABLE SPORTS TEAMS. Forbes, 20I I. Pictures. Disponível em: < http://mww.forbes.com/pictures/mli45fdhk/no- I -manchester-united/>. Acesso em: 8 jan. 2012.

VALOR DE MERCADO DE EMPRESAS LISTADAS NA BOVESPA É RECORDE EM 2010. Folha de São Paulo, São Paulo, 3 jan. 20I I. Mercado. Disponível em: http://www I folha.uol. com.br/mercado/854 I07-valor-de-mercado-de-empresas-listadas-na-bovespa-e-recorde-em-20 l0.shtml.

Recebido em: 17 maio 2012

Aprovado em: 21 mar. 2013

Endereço para correspondência:

Thadeu Miranda Gasparetto

Rua João Faria Júnior, I 53

Bairro Bom Clima Juiz de Fora-MG

CEP: $36046-490$ 